\title{
Insulin resistance, diabetes, and risk markers for ischaemic heart disease in Asian men and non- Asian men in Bradford
}

\author{
T M Knight, Z Smith, A Whittles, P Sahota, J A Lockton, G Hogg, A Bedford, M Toop, \\ E E M Kernohan, M R Baker
}

Clinical Epidemiology

Research Unit

(University of

Bradford),

Department of Public

Health, Bradford

Health Authority,

Bradford, West

Yorkshire

T M Knight

E E M Kernohan

M R Baker

Department of

Dietetics, Bradford

Health Authority,

Bradford, West

Yorkshire

Z Smith

P Sahota

Environmental Health

Department,

Bradford

Metropolitan Council,

Bradford, West

Yorkshire

A Whittles

Department of

Chemical Pathology,

Leeds General

Infirmary, Leeds, West

Yorkshire

J A Lockton

Department of

Clinical Biochemistry,

Bradford Royal

Infirmary, Bradford,

West Yorkshire

G Hogg

Department of

Chemical Pathology,

Harrogate General

Hospital, Harrogate,

North Yorkshire

A Bedford

M Toop

Correspondence to

Dr T M Knight, Department

of Surgery, School of

Postgraduate Medicine and

Biological Sciences,

Thornburrow Drive,

ST4 7QB.

Accepted for publication

5 February 1992
Abstract

Objective-To examine the hypothesis, in a community not studied before, that insulin resistance associated with centralised adiposity is the mechanism underlying the predisposition of Asian immigrant communities to both ischaemic heart disease and diabetes mellitus.

Design-Cross sectional study within one socioeconomic stratum.

Setting-Two factories in the textile sector in Bradford, West Yorkshire.

Subjects-Male manual workers of Asian (110) and non-Asian origin (156) aged $20-65$ years.

Results-Diabetes was almost three times more prevalent in the Asian group. Two hours after an oral glucose load Asian men had double the serum insulin concentrations of non-Asian men ( $p<$ $0.0001)$. Asian men also had significantly lower concentrations of plasma total cholesterol $(p<0.03)$, high density lipoprotein cholesterol (HDL) (HDL, p $<0.0001$; $\mathrm{HDL}_{3}, \mathbf{p}<0.0001$ ), and apolipoprotein AI (p $<0.0001)$. Fasting plasma triglyceride concentrations were slightly higher $(p=0.072)$ in the Asian men; thus the ratio of triglyceride cholesterol was higher $(p=0.006)$. The interrelation between serum insulin and plasma lipid concentrations indicated metabolic differences between the ethnic groups. Insulin concentrations were associated with cholesterol concentrations in the Asian men only and there was a lack of association between triglyceride, low density lipoprotein cholesterol, and HDL cholesterol in this group. The risk marker profile in the Asian men was therefore quite different to that of their non-Asian counterparts and was associated with a greater tendency to centralised adiposity.

Conclusion-These data support the insulin resistance hypothesis and thus have important implications for strategies for the prevention of heart disease in Asian communities in the United Kingdom.

Asian people living in the United Kingdom have a recognised excess of ischaemic heart disease. ${ }^{1}$ In an extensive review, McKeigue et al concluded that high rates of heart disease are common in other groups of Asians originating from the Indian subcontinent and living overseas. ${ }^{2}$ They suggested that the excess rates seen in immigrant Asian communities cannot be explained in terms of the established risk factors for heart disease-that is, raised plasma total cholesterol and high rates of hypertension and smoking. However, studies of such Asian communities by McKeigue et al and other groups indicated that probable risk factors in this group are a higher prevalence of noninsulin-dependent diabetes mellitus, lower plasma high density lipoprotein cholesterol concentrations, and higher triglyceride concentrations. $^{3-7}$

McKeigue et al hypothesised that insulin resistance may be common in these people and that this may be the underlying mechanism leading to both the predisposition to diabetes and the atherogenic lipid profile observed. ${ }^{2} \mathrm{~A}$ similar combination of risk markers was described by Reaven ${ }^{8}$ as "syndrome X", namely, resistance to insulin stimulated glucose uptake, glucose intolerance, hyperinsulinaemia, increased very low density lipoprotein cholesterol, decreased high density lipoprotein cholesterol, and hypertension.

Diabetes, insulin resistance, and cardiovascular disease have separately been associated with a tendency to centralised adiposity, where adipose tissue is deposited preferentially on the trunk and intra-abdominally. ${ }^{9}$ Body fat distribution may therefore have a role in the insulin resistance hypothesis of McKeigue et al and in Reaven's "syndrome X".

In their latest study McKeigue et al tested their hypothesis in a large population survey in London (using factory workers and general practice patients). ${ }^{10}$ The results confirmed the existence of the syndrome in the Asian subjects and this was associated with a greater tendency to centralised adiposity. The population studied was predominantly Sikh (52\%) with $20 \%$ of Hindu and $15 \%$ of Muslim culture. Bradford, West Yorkshire, has a high proportion of residents originating from the Indian subcontinent. In the 1981 census, $15 \%$ of residents were living in households headed by an Asian-born man. ${ }^{11}$ Around two thirds of these were Muslims from Pakistan. It was therefore of interest to investigate the insulin resistance hypothesis in this different Asian community.

This paper describes a study in which a wide 
range of risk markers, both established ones and ones that were relevant to the hypothesis in question, were measured in Asian and nonAsian men resident in Bradford in 1989. Apolipoproteins AI and B were measured because they are the major protein components of the lipoproteins of interest and they have been suggested as predictors of coronary heart disease risk. ${ }^{12}$

\section{Patients and methods}

The protocol for this study was approved by the district ethics committee and informed consent was obtained from all the men.

\section{SUBJECTS}

We studied male, skilled manual workers of Asian and non-Asian origin, aged 20-65 years. They were classified as Asian or non-Asian by name and self-reported origin.

\section{SAMPLING}

Local firms in the traditional textile industry in Bradford were invited to participate in the study. Two factories that responded were selected on the basis of the number of Asian men in the workforce and the comparability of labour both between and within factories. The study was confined to departments where men of both Asian and non-Asian origins worked together. Because participation in the study was voluntary we made every effort to maximise response rates.

\section{PROCEDURE}

The men were asked to complete a lifestyle questionnaire (to obtain demographic details; medical histories; and information on smoking habits, exercise routine, and alcohol use), a food frequency questionnaire, and a three day diet diary. Blood samples were taken during a morning appointment and during an afternoon session; blood pressure was measured, anthropometrical measurements made, and completed questionnaires and diet diaries were checked through with each man. At all times one of the research team (PS) was available to translate into Asian languages.

\section{BLOOD SAMPLES}

The men were asked to fast overnight. Venous blood samples were taken between 7 and $8 \mathrm{am}$, after a minimum of 15 minutes of seated rest, for plasma lipid determinations. Samples for plasma glucose and serum insulin analyses were then taken two hours after ingestion of an oral dose of $75 \mathrm{~g}$ glucose (taken in $330 \mathrm{ml}$ Lucozade). The men fasted over the two hour period.

\section{BLOOD PRESSURE}

These measurements were made with an electronic sphygmomanometer (Copal, Pulse, UK) by one observer only. Two measurements were made while each man was seated. The first was taken after at least 15 minutes' rest to familiarise the subject with the procedure and the second was taken after a further 15 minutes' rest. Only the second readings were used for the present analyses. A systolic pressure of $\geqslant 160 \mathrm{~mm} \mathrm{Hg}$ or a diastolic pressure of $\geqslant 90 \mathrm{~mm} \mathrm{Hg}$ or both were the criteria for raised blood pressure.

\section{LIFESTYLE ASSESSMENT}

Smoking habit was recorded as never, ex, or current; for current smokers the usual number of cigarettes smoked per day was also recorded. Usual consumption of alcoholic beverages was recorded as number of glasses of appropriate size and converted to standard units. The men were asked to list physical activity taken during leisure time on a regular basis-that is, every week for at least 20 minutes each time. These activities were coded as light, moderate, or strenuous according to lists published by the Health Education Authority. ${ }^{13}$

\section{LABORATORY DETERMINATIONS}

Lipid/lipoprotein assays were performed in the Clinical Biochemsitry Department, Harrogate General Hospital. Total plasma cholesterol was measured enzymatically by the method of Allain et $a l,{ }^{14}$ modified for the IL Monarch Centrifugal Analyser. Kits were supplied by Instrumentation Laboratory (UK). Calibration was against a secondary standard supplied by Coulter Electronics. Within batch precision was $1.43 \%$ at a concentration of $6.23 \mathrm{mmol} / 1$ and between batch precision was $2.03 \%$ at a concentration of $6.25 \mathrm{mmol} / \mathrm{l}$. High density lipoprotein cholesterol and its subfractions were measured by the polyethylene glycol precipitation method of Gidez et al ${ }^{15}$ followed by cholesterol measurement as above. Calibration was against a secondary standard (BCL Precilip, UK). Within batch precision was $1.48 \%$ at a concentration of $1.23 \mathrm{mmol} / 1$. Between batch precision was $4.3 \%$ at the same concentration. The secondary standards described above were validated against human serum pools provided by the Center for Disease Control, (CDC), Bethesda, USA and NHLI for their lipid standardisation programs. The concentration of low density lipoprotein cholesterol was calculated by the Friedwald equation. ${ }^{16}$ Triglycerides were measured on an IL Monarch Centrifugal Analyser by a commercially available kit (Instrumentation Laboratories, UK) based on the method of Bucolo and David. ${ }^{17}$ The assay was standardised by calculating triglyceride as the triolein equivalent based on the molar absorption coefficient of NADH. Intra-assay precision was $2.20 \%$ at a concentration of $2.65 \mathrm{mmol} / 1$ and inter-assay precision was $2.63 \%$ at $2.63 \mathrm{mmol} /$ 1. Apolipoproteins AI and B were measured by a turbidometric immunoassay. ${ }^{18}$ The assays were performed on a Monarch 1000 analyser (Instrumentation Laboratories, UK). Standards were referenced to material provided by CDC. The precision of assays both within and between batch was less than $2 \cdot 6 \%$.

Plasma glucose and serum insulin concentrations were determined in the Clinical Biochemistry Department, Bradford Royal Infirmary. Plasma glucose was assayed along with routine NHS specimens, by an enzymatic 
method specific for glucose. Samples were assayed on the same day as collection and thus batch precision data are not available. However, samples were subject to routine quality control procedures. The men were classified as normoglycaemic if their glucose concentration two hours after the oral dose was $<7.0 \mathrm{mmol} / \mathrm{l}$. Impaired glucose tolerance was suspected when concentrations were between 7.0 and $11.0 \mathrm{mmol} / \mathrm{l}$ and diabetes was suspected when concentrations were $\geqslant 11.0 \mathrm{mmol} / 1{ }^{19}$

Serum insulin concentrations were measured by a commercially available kit by Radioimmuno assay (Pharmacia, UK). Within assay precision was below $10 \%$ over the range of concentrations measured. Control sera were supplied with kits for internal quality control. We also used an external quality control system administered by the Department of Biochemistry, Guildford Hospital. Results from the Bradford laboratory were consistently within the cluster of values reported by participating laboratories and were never classed as outliers.

\section{ANTHROPOMETRY}

All anthropometrical measurements were made by one observer only (AW). The men were measured in their underclothes. Weight was measured to the nearest $0.1 \mathrm{~kg}$ and height to the nearest $0.1 \mathrm{~cm}$ with the head parallel to the floor. The body mass index was calculated as the ratio of weight $(\mathrm{kg})$ to the square of height $\left(\mathrm{m}^{2}\right)$. Circumference measurements were made to the nearest $0.1 \mathrm{~cm}$ with a tape measure that had a spring balance attached to ensure consistency of measurement pressure. The circumference of the mid-upper arm was measured at the mid-point between the tips of the acromion and the olecranon. The waist was measured as the smallest circumference between the costal margin and the iliac crest. Hip measurements were made at the level of the most lateral point on the great trochanter. Thigh circumference was measured at the position of maximum girth. Skinfold thicknesses were measured with Holtain calipers to the nearest millimetre at five standard sites: triceps, subscapular, suprailiac, anterior thigh, and suprapatellar. Three measurements were taken at each site on the non-dominant side of the body. Data are prestended as arithmetic means.

STATISTICAL ANALYSES

We analysed questionnaire and clinical data

Table 1 Mean (95\% CI) plasma glucose, lipids and serum insulin concentrations ${ }^{\star}$

\begin{tabular}{|c|c|c|c|}
\hline Variable & $\begin{array}{l}\text { Non-Asian } \\
(n=148)\end{array}$ & $\begin{array}{l}\text { Asian } \\
(n=96)\end{array}$ & $p \dagger$ \\
\hline 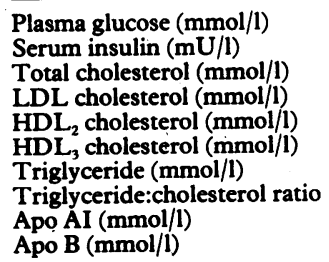 & $\begin{array}{l}3.5(3.4 \text { to } 3.7) \\
10.2(9.1 \text { to } 11.5) \\
5.7(5.5 \text { to } 5.8) \\
3.6(3.5 \text { to } 3.8) \\
0.3(0.3 \text { to } 0.3) \\
1.1(1.0 \text { to } 1.1) \\
1.3(1.2 \text { to } 1.4) \\
0.26(0.23 \text { to } 0.28) \\
1.2(1.2 \text { to } 1.3) \\
0.7(0.6 \text { to } 0.7)\end{array}$ & $\begin{array}{l}3.8(3.7 \text { to } 4.0) \\
22.3(19.3 \text { to } 25.8) \\
5.4(5.2 \text { to } 5.6) \\
3.5(3.3 \text { to } 3.7) \\
0.2(0.2 \text { to } 0.2) \\
0.9(0.8 \text { to } 0.9) \\
1.4(1.3 \text { to } 1.6) \\
0.32(0.29 \text { to } 0.35) \\
1.1(1.1 \text { to } 1.2) \\
0.7(0.6 \text { to } 0.7)\end{array}$ & $\begin{array}{c}0.016 \\
<0.0001 \\
0.030 \\
0.283 \\
<0.0001 \\
<0.0001 \\
0.072 \\
0.006 \\
<0.0001 \\
0.383\end{array}$ \\
\hline
\end{tabular}

* Means for glucose, total, low density lipoprotein (LDL), and high density lipoprotein 3 HDL cholesterol are arithmetic. Means for insulin, $\mathrm{HDL}_{2}$ cholesterol, triglyceride, and apolipoproteins are geometric. All adjusted for age and body mass index $(95 \% \mathrm{CI})$.

tSignificance of $F$, analysis of variance between ethnic groups (with age and body mass index as covariates). with the SPSSX Software Program. Data for plasma triglyceride, high density lipoprotein cholesterol, apolipoproteins and serum insulin concentrations were logarithmically transformed, means are therefore geometric. For parametric statistical tests we used two tailed $p$ values unless indicated otherwise. To investigate univariate associations between variables we used Spearman rank correlations (two tailed $p$ values). Multivariate associations were investigated by multiple regression with stepwise addition and deletion of predictor variables. Dietary data will be reported in a separate paper. Because the dietary methods used (food frequency questionnaire and three day diet diary) allow comparison of mean intakes between groups only these data were not entered into the correlation or regression analyses.

\section{Results}

RESPONSE RATES

Of the eligible men invited to participate, $73.7 \%$ from factory $A$ and $76.2 \%$ from factory $B$ entered the study. The response rate was higher among Asian men $(83.4 \%)$ than nonAsian men (70.6\%). After entering the study 27 men were lost: four owing to long-term sick leave, three left the factory, nine could not fully meet study requiremen because of shift patterns, and 11 withdrew $(3 \cdot 4 \%)$. The range of blood analyses was incomplete for 22 men (owing to lack of material). Thus the analyses presented here are based on complete sets of data from 156 non-Asian and 110 Asian men $(84.4 \%$ of the original sample). In terms of religion, the Asian sample was representative of the Bradford population, with $63.5 \%$ Muslims (Pakistani or Punjabi), $31 \cdot 3 \%$ Hindu (mainly Gujarati), and $5 \cdot 2 \%$ either Sikh or of no stated religion. Because of the small sample sizes the results have not been presented for these subgroups.

AGE

The mean age of both ethnic groups was similar (non-Asians 41.0 years, range 20-65 years; Asians 39.3 years, range $20-62$ years). Data were adjusted for age where appropriate.

\section{BLOOD PRESSURE}

Mean systolic blood pressure was significantly higher in non-Asian men $(137.4 \mathrm{~mm} \mathrm{Hg}, 95 \%$ CI 134.8 to 139.9$)$ than in Asian men (131.4 $\mathrm{mm} \mathrm{Hg}, 95 \%$ CI $128 \cdot 1$ to $134 \cdot 8)(p=0.006)$. Mean diastolic pressure was, however, similar in both groups (non-Asians $79.6 \mathrm{~mm} \mathrm{Hg} \mathrm{(78.0}$ to 81.2 ) and Asians $79.5 \mathrm{~mm} \mathrm{Hg}(77.5$ to 81.6$)$. However, $26.6 \%$ of Asian men in the initial sample were found to have raised blood pressure compared with $23.1 \%(p=0.05)$ of nonAsian men.

\section{DIABETES}

By the criteria set out above, seven non-Asian men and 14 Asian men were classified as having suspected diabetes. Of these 21 men, five $(23.8 \%)$ were undiagnosed upon entry to the study. Diabetes was $2 \cdot 8$ times more common in the Asian men ( $12.7 \%$ v $4.5 \%$; difference $8.2 \%$, 
Table 2 Inter-correlations ${ }^{\star}$ between serum insulin, plasma lipids, and waist-to-hip ratio

\begin{tabular}{|c|c|c|c|c|c|c|c|}
\hline & \multirow{2}{*}{$\begin{array}{l}\text { Waist-to-hip } \\
\text { ratio }\end{array}$} & \multirow{2}{*}{$\begin{array}{l}\text { Serum } \\
\text { insulin }(m U / l)\end{array}$} & \multicolumn{3}{|c|}{ Cholesterol ( $\mathrm{mmol} / \mathrm{l})$} & \multirow{2}{*}{$\begin{array}{l}\text { Triglyceride } \\
(\text { mmol } / l)\end{array}$} & \multirow{2}{*}{$\begin{array}{l}\text { Apolipoprotein } \\
A I(\text { mmol } / l)\end{array}$} \\
\hline & & & $H D L 2$ & $H D L 3$ & $L D L$ & & \\
\hline $\begin{array}{l}\text { Insulin }(\mathrm{mU} / \mathrm{l}): \\
\text { Non-Asian } \\
\text { Asian }\end{array}$ & $\begin{array}{l}0 \cdot 31 \S \\
0.46 \S\end{array}$ & - & - & - & - & - & - \\
\hline $\begin{array}{l}\text { Cholesterol (mm } \\
\text { HDL }_{2} \\
\text { Non-Asian } \\
\text { Asian }\end{array}$ & $\begin{array}{l}-0.24 \ddagger \\
-0.30 \S\end{array}$ & $\begin{array}{l}-0.13 \\
-0.34 \S\end{array}$ & - & - & - & - & - \\
\hline $\begin{array}{l}\mathrm{HDL}_{3}: \\
\text { Non-Asian } \\
\text { Asian }\end{array}$ & $\begin{array}{l}-0.30 \S \\
-0.30 \S\end{array}$ & $\begin{array}{l}-0.20 \dagger \\
-0.35 \S\end{array}$ & $\begin{array}{l}0.69 \S \\
0.64 \S\end{array}$ & - & - & - & - \\
\hline $\begin{array}{l}\text { LDL: } \\
\text { Non-Asian } \\
\text { Asian }\end{array}$ & $\begin{array}{l}0 \cdot 26 \ddagger \\
0 \cdot 14\end{array}$ & $\begin{array}{l}0 \cdot 10 \\
0 \cdot 21 \ddagger\end{array}$ & $\begin{array}{l}-0 \cdot 26 \ddagger \\
-0 \cdot 10\end{array}$ & $\begin{array}{l}-0.29 \S \\
-0.07\end{array}$ & - & - & - \\
\hline $\begin{array}{l}\text { Triglyceride (mn } \\
\text { Non-Asian } \\
\text { Asian }\end{array}$ & $\begin{array}{l}0.47 \S \\
0.46 \S\end{array}$ & $\begin{array}{l}0 \cdot 33 \S \\
0 \cdot 31 \S\end{array}$ & $\begin{array}{l}-0.44 \$ \\
-0.46 \$\end{array}$ & $\begin{array}{l}-0.55 \S \\
-0.47 \S\end{array}$ & $\begin{array}{l}0 \cdot 28 \S \\
0 \cdot 15\end{array}$ & - & - \\
\hline $\begin{array}{l}\text { Apolipoprotein } \\
\text { AI: } \\
\text { Non-Asian } \\
\text { Asian }\end{array}$ & $\begin{array}{r}-0.10 \\
0.07\end{array}$ & $\begin{array}{l}-0.15 \\
-0.04\end{array}$ & $\begin{array}{l}0.62 \S \\
0.45 \S\end{array}$ & $\begin{array}{l}0.74 \S \\
0.67 \S\end{array}$ & $\begin{array}{l}-0 \cdot 10 \\
-0 \cdot 01\end{array}$ & $\begin{array}{l}-0.17 \dagger \\
-0.01\end{array}$ & - \\
\hline $\begin{array}{l}\text { B: } \\
\text { Non-Asian } \\
\text { Asian }\end{array}$ & $\begin{array}{l}0.46 \S \\
0.40 \S\end{array}$ & $\begin{array}{l}0 \cdot 28 \\
0.36 \S\end{array}$ & $\begin{array}{l}-0.46 \S \\
-0.41 \S\end{array}$ & $\begin{array}{l}-0.52 \S \\
-0.39 \S\end{array}$ & $\begin{array}{l}0.70 \S \\
0.79 \S\end{array}$ & $\begin{array}{l}0.80 \S \\
0.80 \S\end{array}$ & $\begin{array}{c}-0.24 \S \\
0.05\end{array}$ \\
\hline
\end{tabular}

«Spearman rank correlation coefficient $(r)$ with significance $(p)$ (two tailed) $<0.05 \dagger, 0.01 \ddagger, 0.0001 \S$ given for non-Asian men $(n=148)$ and Asian men $(n=96)$.

$95 \%$ CI 1.2 to $15.2 \mathrm{p}<0.02$ ). Only one, a nonAsian man had a two hour glucose concentration within the range for impaired glucose tolerance. For all the other analyses, we used the data for normoglycaemic men only (that is, 148 non-Asian men and 96 Asian men).

\section{SERUM INSULIN, PLASMA GLUCOSE, LIPIDS AND} LIPOPROTEINS

Mean glucose concentrations two hours after an oral dose were significantly higher in Asian men $(p=0.016)$ even though at the same time their serum insulin concentrations were over double those of non-Asian men $(p<0.0001)$ (table 1). There were significant positive correlations between glucose and insulin concentrations in both Asian $(r=0.514 p<$ $0.0001)$ and non-Asian men $(r=0.566 \mathrm{p}<$ 0.0001 )

Asian men had significantly lower mean concentrations of total $(p=0.03)$ and high density lipoprotein cholesterol $(p<0.0001$ for both subfractions) and apolipoprotein AI ( $p<$ 0.0001 ). Mean concentrations of low density lipoprotein cholesterol were similar in both ethnic groups. The higher triglyceride concentration in Asian men was of borderline significance $(0.05<p<0.1)$. The ratio of

Table 3 Anthropometric measurements (age adjusted arithmetic means (95\% confidence interval

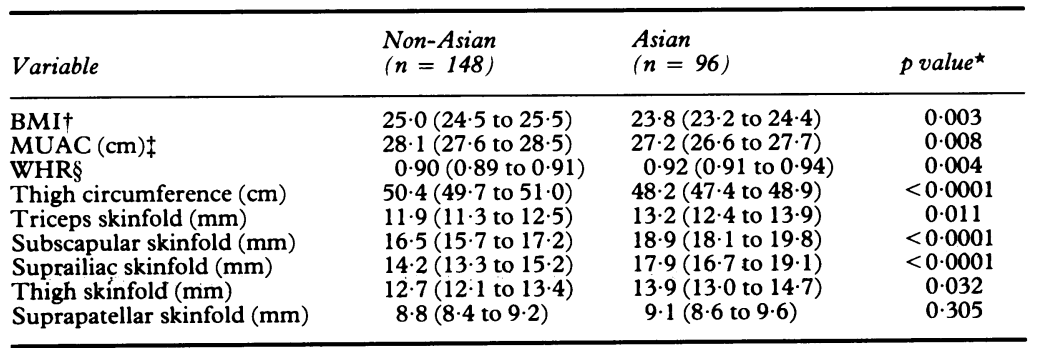

« Significance of $F$, analysis of variance between ethnic groups (age in years as covariate) † Body mass index: weight/ height $^{2}$.

†Mid upper arm circumference $(\mathrm{cm})$

$\$$ Ratio of waist (at least circumference) $(\mathrm{cm})$ to hip circumference $(\mathrm{cm})$. triglyceride to cholesterol was significantly higher in Asian men ( $p=0.006)$. Mean concentrations of apolipoprotein B were the same for both groups.

ASSOCIATIONS BETWEEN SERUM INSULIN AND PLASMA LIPIDS

In both ethnic groups there were significant $(\mathrm{p}<0.0001)$ positive correlations between insulin and triglyceride concentrations (table 2). Insulin was significantly and positively correlated with low density lipoprotein cholesterol and apolipoprotein B in Asian men ( $p<0.01$ and $\mathrm{p}<0.0001$ ) but not in nonAsian men. Similarly, insulin was strongly inversely correlated with high density lipoprotein cholesterol in Asian men ( $p<0.0001$ for both subfractions) whereas in non-Asian men there was a weak correlation with $\mathrm{HDL}_{3}$ cholesterol only $(\mathrm{p}<0.05)$.

\section{INTRA-LIPID CORRELATIONS}

Inter-ethnic differences were seen, in that significant inverse correlations between both high density lipoprotein cholesterol subfractions and low density lipoprotein cholesterol ( $p<$ $0.01, p<0.0001)$ and between apolipoprotein $B$ and apolipoprotein AI $(p<0.0001)$ were found only in the non-Asian group. Similarly, the positive correlation between low density lipoprotein cholesterol and triglycerides was only significant in non-Asians $(\mathrm{p}<0.0001)$.

\section{ANTHROPOMETRY}

Table 3 shows the anthropometric data. The mean body mass index was significantly lower in the Asian group ( $p=0.003$ ). Mid upper arm (upper body) and thigh (lower-body) circumferences were significantly greater in non-Asian men $(p=0.008, p<0.0001)$. In contrast, the mean waist-to-hip ratio was higher in Asian men $(p=0.004)$. Skinfold thicknesses were greater in Asian men at all sites, but the ethnic differences in mean thickness were greatest for 
Table 4 Smoking habits, exercise routine, and usual alcohol consumption

\begin{tabular}{lcll}
\hline Data & $\begin{array}{l}\text { Non-Asian } \\
(n=148)\end{array}$ & $\begin{array}{l}\text { Asian } \\
(n=96)\end{array}$ & p value \\
\hline Smokers & $65(43.9 \%)$ & $42(43.8 \%)$ & $\mathrm{p}>0.05$ \\
Cigarettes per day $\dagger$ & $15.5(13.3$ to 17.6$)$ & $9.6(6.9$ to 12.4$)$ & 0.001 \\
Alcohol consumers & $138(93.2 \%)$ & $35(36.5 \%)$ & $<0.0001$ \\
Units per week & $24.3(21.0$ to 27.7$)$ & $19.5(12.6$ to 26.2$)$ & 0.203 \\
Strenuous exercise & $122(82.4 \%)$ & $87(90.6 \%)$ & $>0.05$ \\
\hline
\end{tabular}

^Significance of $F$, analysis of variance between ethnic groups for group means and significance of difference between two proportions.

tAmong smokers only.

‡Number (\%) not taking regular exercise (at least once a week for at least 20 minutes).

the truncal subscapular and suprailiac sites (both $\mathrm{p}<0.0001$ ). Triceps and thigh skinfolds were only moderately thicker $(p=0.011$ and $\mathrm{p}=0.032$ ) and suprapatellar skinfold thicknesses showed no ethnic variation. Because the waist-to-hip ratio is a reliable measure of centralised adiposity, ${ }^{20}$ the following results are presented for this anthrompometric measurement only.

ASSOCIATIONS BETWEEN WAIST-TO-HIP RATIO, SERUM INSULIN, AND PLASMA LIPIDS

Strong $(p<0.0001)$ positive correlations were found between insulin concentrations and waist-to-hip ratio in both ethnic groups (table 2 ), although the correlation coefficient was higher for the Asian group. Triglyceride and apolipoprotein B concentrations were positively correlated $(p<0.0001)$ with waistto-hip ratio in both ethnic groups; low density lipoprotein cholesterol was correlated with this

Table 5 Multivariate associations ${ }^{\star}$ between variables implicated in the insulin resistance syndrome ${ }^{2}$

\begin{tabular}{|c|c|c|}
\hline \multirow[b]{2}{*}{ Relation } & \multicolumn{2}{|c|}{$R^{2}$ statistic (cumulative) } \\
\hline & $\begin{array}{l}\text { Non-Asians } \\
(n=148)\end{array}$ & $\begin{array}{l}\text { Asians } \\
(n=96)\end{array}$ \\
\hline $\begin{array}{l}\text { Insulin related to: } \\
2 \mathrm{~h} \text { glucose }(\mathrm{mmol} / \mathrm{l})(+) \\
\text { Triglyceride }(\mathrm{mmol} / \mathrm{l})(+) \\
\text { Waist:hip ratio }+) \\
\text { Apolipoprotein }(+) \\
\text { p value }\end{array}$ & $\begin{array}{l}0.316 \\
0.386 \\
= \\
<0.0001\end{array}$ & $\begin{array}{c}0.256 \\
-\quad \\
0.421 \\
0.454 \\
<0.0001\end{array}$ \\
\hline $\begin{array}{l}\text { Total HDL cholesterol related to: } \\
\mathrm{HDL}_{3} \text { cholesterol }(\mathrm{mmol} / \mathrm{l})(+) \\
\mathrm{HDL}_{2} \text { cholesterol }(\mathrm{mmol} / \mathrm{l})(+) \\
\mathrm{p} \text { value }\end{array}$ & $\begin{array}{c}0.935 \\
0.993 \\
<0.0001\end{array}$ & $\begin{array}{c}0.921 \\
0.991 \\
<0.0001\end{array}$ \\
\hline $\begin{array}{l}\mathrm{HDL}_{3} \text { cholesterol related to: } \\
\text { Apolipoprotein } \mathrm{AI}(\mathrm{mmol} / \mathrm{l})(+) \\
\text { Triglyceride }(\mathrm{mmol} / \mathrm{l})(-) \\
\mathrm{HDL}_{2} \text { cholesterol }(\mathrm{mmol} / \mathrm{l})(+) \\
\text { p value }\end{array}$ & $\begin{array}{c}0.534 \\
0.714 \\
0.729 \\
<0.0001\end{array}$ & $\begin{array}{r}0.443 \\
0.659 \\
-\quad 0.0001\end{array}$ \\
\hline $\begin{array}{l}\text { Apolipoprotein AI related to: } \\
\text { HDL cholesterol (mmol/l)(+) } \\
\text { Triglyceride (mmol/l)(-) } \\
\text { Strenuous exercise (frequency) (+) } \\
\text { Alcohol intake (units/week)(+) } \\
\text { Apolipoprotein B (mmol/l) (-) } \\
\text { p value }\end{array}$ & $\begin{array}{r}0.553 \\
0.629 \\
0.639 \\
0.648 \\
-\quad 0.0001\end{array}$ & $\begin{array}{l}{ }^{0.406} \\
= \\
- \\
<0.541 \\
<0.0001\end{array}$ \\
\hline $\begin{array}{l}\text { Triglyceride related to: } \\
\text { Apolipoprotein B (mmol/l) (+) } \\
\text { LDL cholesterol (mmol/l) (+) } \\
\text { Alcohol intake (units/week)(+) } \\
\text { HDL cholesterol (mmol/l) (-) } \\
\text { Waist:hip ratio (+) } \\
\text { p value }\end{array}$ & $\begin{array}{r}0.611 \\
0.753 \\
0.766 \\
0.782 \\
-\quad 0.0001\end{array}$ & $\begin{array}{l}0.626 \\
0.833 \\
-\quad \\
-\quad 0.838 \\
<0.0001\end{array}$ \\
\hline $\begin{array}{l}\text { Apolipoprotein B related to: } \\
\text { Triglyceride }(\mathrm{mmol} / \mathrm{l})(+) \\
\text { LDL cholesterol }(\mathrm{mmol} / \mathrm{l}(+) \\
\text { p value }\end{array}$ & $\begin{array}{c}0.611 \\
0.864 \\
<0.0001\end{array}$ & $\begin{array}{c}0.630 \\
0.899 \\
<0.0001\end{array}$ \\
\hline
\end{tabular}

*Multiple regression with stepwise addition and deletion of variables. Statistic given is adjusted $\mathbf{R}^{2}$ (cumulative) for the regression equation after addition of each predictor variable. The $p$ value is the significance of the $F$ value for the complete equation-that is, significance of combined predictor variables. Predictor variables were all previously found to contribute significantly and independently to variance of the dependent variables. The sign in parentheses shows the direction of the relation.

HDL, high density lipoprotein; LDL, low density lipoprotein. ratio in non-Asians only $(\mathrm{p}<0.01)$. There were inverse correlations between waist-to-hip ratio and high density lipoprotein cholesterol; the weakest correlation was seen in non-Asians for $\mathrm{HDL}_{2}$ cholesterol ( $\mathrm{p}<0.01$, others $\mathrm{p}<0.0001$ ). No significant correlations between apolipoprotein $\mathrm{AI}$ and waist-to-hip ratio were found.

\section{SMOKING, EXERCISE, AND ALCOHOL}

Table 4 gives details of these aspects of lifestyle. The proportion of non-Asian mean who were current smokers $(43.9 \%)$ was similar to the proportion among Asian men (43.8\%). However, non-Asian smokers smoked more cigarettes per week on average than Asian smokers $(p=0.001)$. Most $(93.2 \%)$ of the non-Asian men regularly consumed alcoholic beverages whereas only $36.5 \%$ of Asian men did. Among alcohol consumers, non-Asian men drank on average more units weekly than Asian consumers, although the difference was not significant. Most $(82.4 \%)$ of the non-Asian men and even more Asian subjects $(90.6 \%)$ did not take strenuous exercise regularly.

\section{MULTIVARIATE ANALYSES}

We investigated the associations between the biochemical, anthropometrical, and lifestyle variables by multiple regression analyses (stepwise addition and deletion). Predictor variables were chosen according to biological relevance and the strength of the univariate correlation with each dependent variable and were entered into the equation in order of decreasing strength of this univariate correlation. Table 5 summarises the results of these analyses. Only significant ( $5 \%$ level) independent predictors are shown, along with the cumulative (adjusted) $R^{2}$ with the significance ( $F$ value) of the contribution of combined predictors after allowance for other terms in the equation.

Two hour glucose concentrations and triglyceride concentrations were significant independent predictors of two hour insulin concentrations in non-Asian men; together they accounted for $38.6 \%$ of the total variance. In Asian men two hour glucose, waist-to-hip ratio, and apolipoprotein $B$ concentrations made significant contributions; together they accounted for $45.4 \%$ of the total insulin variance.

Total high density lipoprotein cholesterol concentrations were almost completely dependent upon the variance of the $\mathrm{HDL}_{3}$ subfraction in both ethnic groups. In turn, $\mathrm{HDL}_{3}$ cholesterol concentrations were significantly related to apolipoprotein $\mathrm{AI}$ and triglyceride concentrations. Together these accounted for $65.9 \%$ of total variance in Asian men and $71.4 \%$ in non-Asian men. In non-Asian men the $\mathrm{HDL}_{2}$ concentration was also found to be a significant predictor.

Apolipoprotein AI concentrations were related to high density lipoprotein cholesterol and triglyceride concentrations in non-Asian men, whereas in Asian men high density lipoprotein cholesterol and apolipoprotein B concentrations were significant independent predictors. In Asian men $54 \cdot 1 \%$ of total 
apolipoprotein AI variance was explained by these predictors only. In non-Asian men the inclusion of frequency of strenuous exercise and usual weekly alcohol consumption also made significant improvements to the model, so that a total of $64.8 \%$ of the variance was explained.

Triglyceride, apolipoprotein B, and low density lipoprotein cholesterol concentrations were closely inter-related in both ethnic groups. However, in non-Asian men alcohol consumption and high density lipoprotein cholesterol concentration also contributed to triglyceride variance, whereas in Asian men the waist-to-hip ratio was a significant independent predictor.

\section{Discussion}

We found clear differences in the frequency of risk markers between Asian and non-Asian men. Asian men showed a pattern of risk markers similar to that described by McKeigue et al for other immigrant Asian communities in the United Kingdom ${ }^{310}$ that was consistent with the "syndrome X" described by Reaven, ${ }^{8}$ that is: raised concentrations of serum insulin in response to glucose, poorer glucose tolerance, decreased plasma high density lipoprotein cholesterol, raised plasma triglyceride, and an increased risk of noninsulin-dependent diabetes mellitus. "Syndrome $\mathrm{X}$ " also includes hypertension. We found limited evidence of an increased tendency to raised blood pressure in our Asian group. Others found higher blood pressure or a higher prevalence of hypertension among Asian groups; ${ }^{3610}$ and mortality from strokes was recently reported to be $53 \%$ higher in Asian men $^{1}$ than the United Kingdom average.

Reaven postulated that where there is resistance to insulin stimulated glucose uptake, deterioration of glucose tolerance can only be prevented if the $\beta$ cells are able to maintain increased insulin secretion. If this state of hyperinsulinaemia cannot be maintained then loss of glucose tolerance would result, followed by overt diabetes mellitus. Thus a state of hyperinsulinaemia resulting from insulin resistance would be characteristic of individuals or groups at increased risk of diabetes. ${ }^{8}$ In our study, serum insulin concentrations in Asian men two hours after glucose loading were over double those of the non-Asian men and yet tolerance was poorer (although still normal) in Asian men. The prevalence of diabetes in the total sample was nearly three times higher in Asian men. Thus there were clear signs of insulin resistance in our, as yet, healthy and normoglycaemic Asian men, who were at an increased risk of diabetes. Three other published studies have measured these variables in Asian communities in the United Kingdom. All three reported insulin concentrations after glucose loading to be at least twice as high in Asian men as in non-Asian men and diabetes to be two ${ }^{3}$ and four ${ }^{70}$ times more prevalent in the Asian communities.

The association between insulin resistance and an increased risk of atherosclerosis may be mediated through the reduced concentrations of plasma high density lipoprotein cholesterol and raised concentrations of plasma triglyceride associated with increased insulin concentrations. The exact mechanisms at work have not yet been fully elucidated but they may involve both an increase in the synthesis of very low density lipoprotein triglyceride (owing to a lack of suppression of adipocyte triglyceride lipase by insulin) and reduced clearance of very low density lipoprotein from the very low density/intermediate density/low density lipoprotein metabolic pathway (caused by lack of stimulation of lipoprotein lipase in adipose tissue by insulin). The result would be a saturation of the pathway and thus an increase in plasma triglyceride concentrations and in the ratio of plasma triglyceride to cholesterol ${ }^{2122}$ as seen in the Asian men. The lack of association between triglyceride, low density lipoprotein and high density lipoprotein cholesterol, and apolipoproteins AI and B in the Asian men certainly accords with this suggested disturbance in lipoprotein metabolism. Plasma triglyceride and high density lipoprotein cholesterol concentrations were inversely correlated in both groups as was reported elsewhere. ${ }^{23}$ Overall the inverse correlation between serum insulin and plasma high density lipoprotein cholesterol concentrations was significant only in Asian men. Likewise, a significant positive association between insulin and both low density lipoprotein cholesterol and apolipoprotein $B$ concentrations was found for Asian men only.

Though inferences made from correlational data such as these are limited, our results seem to support the conclusion that the Asian men were showing signs of a disturbance of lipid and lipoprotein metabolism consistent with an atherogenic lipid profile and that this was associated with insulin insensitivity.

In addition to the associations found between insulin and lipid concentrations, strong associations were also seen between an increased tendency to centralised adiposity (represented by the waist-to-hip ratio) and increasing insulin, triglyceride, and apolipoprotein B concentrations and decreasing high density lipoprotein cholesterol concentrations. Such associations have been reported before. ${ }^{9}$ However, our Asian men showed a significantly greater tendency to centralised adiposity-that is, a greater waist-tohip ratio and greater subscapular and suprailiac skinfold thickness, even though their mean body mass index was lower than that of the non-Asian men. Furthermore, the positive association between waist-to-hip ratio and serum insulin concentrations was strongest in the Asian men.

Multivariate analyses were undertaken to explore further these inter-relations. As may have been predicted, glucose and insulin were associated in both ethnic groups as were high density lipoprotein cholesterol and apolipoprotein AI and triglyceride/low density lipoprotein cholesterol/apolipoprotein B. However, of most interest here were the ethnic differences in associations. The waist-to-hip ratio was a significant independent predictor of 
variance in insulin and triglyceride concentrations in Asian men only. Alcohol consumption and frequency of strenuous exercise were significant contributors in non-Asian men only. Results from multivariate analyses such as these should of course, not be taken to imply cause and effect; variables included were measured with varying degrees of precision and this can amplify or reduce the strength of associations. However, our results do confirm that central adiposity and the "syndrome X" factors are interrelated in Asians and that the interrelation between insulin and lipid metabolism shows ethnic variation.

Our results are remarkably similar, both qualitatively and quantitatively, to the results from McKeigue et al's most recent study. ${ }^{10}$ In the London community studied, the Asian subjects had a higher prevalence of diabetes, higher insulin and triglyceride concentrations after glucose loading and lower high density lipoprotein cholesterol concentrations. Mean waist-to-hip ratios and truncal skinfold thickness were higher in the Asian group. The results of our correlational analyses also accord with those reported by McKeigue et al.

Because McKeigue et al studied more people they were able to analyse their data by religious subgroup. In Muslims and Hindus the results for diabetes prevalence insulin and triglyceride concentrations after glucose loading, and measures of central adiposity were similar. We too found no differences between our smaller groups of Muslims and Hindus for these variables (except for triglyceride concentrations after glucose loading, which we did not measure) and also no difference in mean blood pressure. The insulin resistance hypothesis seems to apply equally to both cultures and McKeigue et al concluded that because heart disease mortality is high in Hindus, Sikhs, and Muslims, these findings point to the insulin resistance syndrome as the most plausible explanation for their excess risk. However, McKeigue et al found within Asian variation for some variables; that is, smoking rates, blood pressure, plasma total cholesterol, and high density lipoprotein cholesterol. We too found higher smoking rates and lower high density lipoprotein cholesterol concentrations in Muslims; and fasting triglyceride concentrations were also higher in this group. These differences are consistent with our dietary information. This is to be reported separately, but in brief, the Muslim diet was higher in meat and lower in vegetables than the Hindu diet, with a resulting lower ratio of polyunsaturated to saturated fatty acids $(0.4 v 0.6, \mathrm{p}<0.01)$. Only three (4.9\%) Muslims drank alcohol regularly, whereas $27(90 \%)$ of Hindus did, but at a moderate level (mean intake 15.4 units per week). Moderate alcohol consumption has been associated with increased concentrations of high density lipoprotein cholesterol. ${ }^{24}$

One hypothesis suggests that diabetes mellitus is the modern result of a thrifty genotype that is capable of overproduction of insulin as an energy conserving mechanism under conditions of periodical famine and low energy intake. ${ }^{25} \mathrm{An}$ increased incidence of diabetes would therefore be expected in a people transported from such an environment into urban British life. One recent study has compared British Asian residents in Manchester with Asian residents in India (both groups originating from the north west of India). The prevalence of diabetes mellitus and insulin concentrations two hours after glucose loading were, however, similar in both groups, although both were substantially higher than those measured in a British non-Asian control group (Dr J Dhawan, personal communication). Perhaps a comparison of very carefully selected groups with completely contrasting lifestyles would shed more light on aetiology.

If, as our studies suggest, centralised body fat distribution and insulin resistance do play an important part in the predisposition of immigrant Asian communities to atherosclerosis, then there are important implications for prevention. Although smoking, high plasma total cholesterol, and hypertension when present are still likely to confer an increased risk of heart disease in Asian people, perhaps preventive strategies aimed at Asian communities should also target the reduction of the waist-to-hip ratio. How feasible this would be depends on whether central adiposity is an acquired or genetic trait. As yet this is still a subject of debate. ${ }^{9}$ A recent study, however, has shown that habitual aerobic exercise reduced the waist-to-hip ratio and also had a beneficial effect in reducing plasma triglycerides and increasing high density lipoprotein cholesterol (Wood, unpublished). Although we can not be sure that the "strenuous" exercise recorded here was aerobic, the significant and independent association between frequency of strenuous exercise and apolipoprotein AI concentrations (and therefore indirectly with high density lipoprotein cholesterol concentrations) that we found accords with the results above. The fact that this association was not seen in Asians, who showed even less inclinication than the non-Asians, to take such exercise regularly suggests that this is one facet of heart disease prevention that needs considerable emphasis in Asian communities.

In our original sample the prevalence of diabetes was almost three times higher in Asian men than in non-Asian men. Almost one quarter of those men classified as diabetic in this study were undiagnosed at entry. We gained the impression that the level of understanding of diabetes among the Asian men was low and compliance with dietary controls was poor. Thus the early detection and control of diabetes also needs to be given greater emphasis in preventive strategies in Asian communities.

We recognise that selection of subjects from male manual workers employed in only two factories in Bradford and a response rate of less than $100 \%$ may limit the relevance of our conclusions to other populations. However, the consistency between our data and those of McKeigue et al's London studies suggests that our results are not chance findings arising from selection bias but that they do indeed have a wider application. 


\section{CONCLUSIONS}

Our data, from a different Asian community in the United Kingdom than previously studied, provide further evidence to support McKeigue et al's hypothesis that body fat distribution and insulin resistance are of aetiological importance in diabetes and heart disease in immigrant Asian communities living overseas. Strategies for preventing heart disease in mixed ethnic communities need to be reviewed, with greater emphasis being placed on control of diabetes, central adiposity, and increased physical activity in Asian communities.

We thank Dr P McKeigue for help and advice during the planning of this study, Sister V Simpson-Clegghorn and the other nurses for their skilled help, the departments of Clinical Biochemistry and Haematology (Bradford Royal Infirmary) and Chemical Pathology (Harrogate General Infirmary and Leeds General Infirmary) for excellent technical assistance, Dr Jackie McCluney for her help, Mrs Carol Stainton for statistical advice, and Mrs Janice Joyce for secretarial help.

1 Barlarajan R. Ethnic differences in mortality from ischaemic heart disease and cerebrovascular disease in England and heart disease and cerebrovascular

2 McKeigue PM, Miller GJ, Marmot MG. Coronary Heart Disease in South Asians overseas: a review. J Clin Epidemiol 1989;42:597-509.

3 McKeigue PM, Marmot MG, Syndercombe Court YD, Cottier DE, Rahman S, Riemersma RA. Diabetes, hyperinsulinaemia, and coronary risk factors in Bangladeshis in East London. Br Heart J 1988;60:390-6.

4 Rubenstein AH, Seftel HC, Miller K, Bersohn I, Wrigh AD. Metabolic response to oral glucose in healthy South African White, Indian, and African subjects. Br Med 1969;i:748-51.

5 Miller GJ, Beckles GLA, Alexis SD, Byam NTA, Price SGL. Serum lipoproteins and susceptibility of men of Indian descent to coronary heart disease. Lancet 1982;i:200-3.

6 Miller GJ, Kotecha S, Wilkinson WH, et al. Dietary and other characteristics relevant to coronary heart disease in other characteristics relevant to coronary heart disease in men of Indian, West Indian, and Eur

7 Hughes LO, Cruickshank JK, Wright J, Raftery EB. Disturbances of insulin in British Asian and white men surviving myocardial infarction. Br Med J 1989;299:537-41.

8 Reaven GM. Role of insulin resistance in human disease. Diabetes 1988;37:1595-1607.
9 Stern MP, Haffner SM. Body fat distribution and hyperinsulinaemia as risk factors for diabetes and cardiovascular disease. Arteriosclerosis 1986;6:123-130.

10 McKeigue PM, Shah B, Marmot MG. Relation of central obesity and insulin resistance with high diabetes prevalence and cardiovascular risk in South Asians. Lancet 1991;337:382-6.

11 Kernohan EEM. The Health of Bradford, Bradford Health Authority Annual Report, 1988.

12 Kukita H, Hamada M, Hiwada K, Kokubu T. Clinical significance of measurements of serum apolipoprotein A-I, A-II, and B in hypertriglyceridaemic male patients with and without Coronary Artery Disease. Atherosclerosis 1985;55:143-9.

13 Health Education Authority. Beating heart disease. London: Health Education Authority.

14 Allain CC, Poon LS, Chan CSG, Richmond W, Fu PC Enzymatic determination of total serum cholesterol. Clin Chem 1974;20:470.

15 Gidez LI, Miller GJ, Burstein M, Scagle S, Elder HA. Separation and quantitation of subclasses of human plasma HDL by a simple precipitation procedure. $J$ Lipid Res 1982;23:1206-23.

16 Friedwald WT, Levy RI, Fredrickson DS. Estimation of serum low-density lipoprotein cholesterol without the use of the preparative centrifuge. Clin Chem 1972;18:499-502.

17 Bucolo G, David H. Quantitative determination of serum triglycerides by the use of enzymes. Clin Chem 1973;19: $476-82$.

18 Rifai N, King ME. Immunoturbidometric assays of apolipoprotein A, AI, AII, and B in serum. Clin Chem 1986;32:957-61.

19 Report of a WHO study group. WHO Tech Rep Ser 1985; 727:11.

20 Ashwell M, Cole TJ, Dixon AK. Obesity: new insight into the anthropometric classification of fat distribution show by computed tomography $B r$ Med J 1985;290:1692-4

21 Tobey TA, Greenfield M, Kraemer F, Reaven GM Relationship between insulin resistance, insulin secretion, very low density lipoprotein kinetics, and plasm triglyceride levels in normotriglyceridaemic man Metabolism 1981;30:165-71.

22 Garg A, Helderman JH, Koffler M, Ayuso R, Rosenstock J, Rashkin P. Relationship between lipoprotein levels and invivo insulin action in normal white young men. Metabolism 1988;37:982-7.

23 Davis CE, Gordon D, LaRosa J, Wood PDS, Halperin M Correlations of plasma high density lipoprotein cholesterol levels with other plasma lipid and lipoprotein concentrations. Circulation 1980;62(suppl IV):24-30.

24 Heiss G, Johnson NJ, Reiland S, Davis CE, Tyroler HA The epidemiology of plasma high-density lipoprotein cholesterol levels. The Lipids Research Clinic Program Prevalence Study Summary. Circulation 1980;62(suppl Prevalence

25 Neel JV. Diabetes mellitus: a "thrifty" genotype rendered detrimental by "progress"? Am J Hum Genet 1962;14 353-62. 